\title{
Internettbaserte selvhjelpsverktøy mot depresjon: Utfordringer og strategier ved implementering
}

\author{
Av Egil Haga, Hanne Sofie Wernø Nilsson, Simen Aurstad Gjernes og Ingunn Legard
}

\section{SAMMENDRAG}

Internettbaserte selvhjelpsverktøy, basert på kognitiv atferdsterapi (iKAT), har de senere årene blitt introdusert for å gjøre behandling mot depresjon mer tilgjengelig. Dette er særlig aktuelt for personer med milde til moderate former for depresjon. Forskningen viser at iKAT er like effektiv som ordinær kognitiv atferdsterapi (KAT) når den gjennomføres med veiledning av helsepersonell. Effekten av verktøyene er nært knyttet til implementeringskvalitet. Barrierer for implementering i primærhelsetjenesten viser seg blant annet å være utfordringer med å innføre nye rutiner i konkurranse med eksisterende tiltak, ha tid til tilstrekkelig opplæring av helsepersonell som skal ta verktøyet i bruk for sine pasienter og manglende systematikk i implementeringen. Helsemyndighetene har gjennom Direktoratet for e-helse initiert etableringen av en felles mestringsportal der slike selvhjelpsverktøy skal gjøres tilgjengelige for helsepersonell og befolkningen. En slik felles plattform vil styrke implementeringen. I tillegg er det behov for prosjekter der man spesifikt monitorerer og evaluerer implementering av slike verktøy som grunnlag for å utforme en systematisk implementeringsstrategi. Som eksempel på et enkelttiltak foreslår vi at implementeringskvaliteten kan styrkes ved å gi bedre opplæring og oppfølging av veilederne, særlig gjelder dette innholdet og omfanget av veiledningen med tanke på å styrke etterlevelse og motvirke drop-out.

\section{ABSTRACT}

Internet-based self-help programmes, based on cognitive behavioural therapy (iCBT), have over the past years been introduced to increase access to treatment for depression. Research show that iCBT is equally effective as ordinary cognitive behavioural therapy (CBT) when offered with guidance and support by health personnel. The effectiveness is closely related to quality of implementation. Known barriers for implementation in primary health care are challenges related to introducing new practices that are competing with already existing routines, having sufficient time for training of health personnel that will include the new tools in their practice, and lack of a systematic approach to implementation. The Norwegian Directorate of eHealth has recently initiated a new portal for e-health tools in order to make such tools more accessible for users and health personnel, and to strengthen implementation. Additionally, there will be a need for projects where implementation of iCBT in routine practice is monitored and assessed so that more systematic strategies for implementation can be developed. We also propose that the quality of implementation may be strengthened by providing better training and follow-up of health personnel who are guiding users of the tools, to increase compliance and reduce drop-out rates. 
pasientene, dernest presentere de utfordringene man kan møte i implementeringen av e-helse-verktøy og til slutt diskutere mulige strategier for implementeringen.

\section{Er iKAT en effektiv behandling mot depresjon?}

En rekke randomiserte kontrollerte studier har undersøkt effekten av iKAT, også for andre psykiske lidelser enn depresion, og det er giort flere metaanalyser av disse studiene. Man skiller mellom studier gjennomført i en kontrollert setting, f.eks. i forbindelse med en klinisk studie innenfor en spesialisert klinikk, der intervensionen følger en spesifikk protokoll (effektstudier, 'efficacy' på engelsk) og studier av hvordan behandlingen virker i ordinær praksis, som for eksempel slik behandlingen ville blitt giennomfort under mindre kontrollerte og optimale betingelser av en fastlege (effektivitetsstudier, 'effectiveness' på engelsk).

Metaanalyser av effektstudier tyder på at iKAT har like god effekt som ordinær samtalebehandling (Andersson et al., 2014; Cuijpers et al., 2010), og at veiledet iKAT mot depresjon gir bedre effekt sammenlignet med ikke-veiledet.

\section{I deler av verden har store avstander til behandlingstilbud spilt en særlig viktig rolle i utviklingen av telemedisinske og internettbaserte behandlingstilbud.}

Nyere metaanalyser dokumenterer iKAT's effektivitet også i ordinær praksis (Andrews et al., 2018; Etzelmueller et al., 2020), men for å konkludere med dette er det behov for flere studier. I den forbindelse vil det være aktuelt å studere iKAT's effektivitet i lys av implementeringsarbeid (se egen del senere i artikkelen), og særlig helsearbeiderens rolle i det veiledede formatet. Framtidig forskning bør ha et særlig fokus på omfanget av veiledningen, veilederens kompetanse samt innholdet i støtten som veilederen gir, for å kunne drøfte hva som er det optimale forholdet mellom støtte og selvhielp (Andrews et al., 2018). Dette vil ha betydning for pasientenes etterlevelse og hvor stor andel av pasientene som dropper ut av behandlingen. Til nå tyder forskningen på at veiledet selvhjelp gir bedre etterlevelse og lavere dropout-rate (Andersson et al., 2014), men man kan tenke seg at gode, brukervennlige programmer vil kunne redusere behovet for veiledning og at denne kan bestå av praktisk/teknisk oppfølging for å styrke etterlevelse (Johansson \& Andersson, 2012; Varga et al., 2020).

Hvorvidt en behandling er kostnadseffektiv er av særlig betydning for beslutningstagere i helsevesenet og hvordan de vurderer implementering. Det er noe forskningsmessig støtte for at veiledet iKAT er kostnadseffektiv sammenlignet med andre behandlingsalternativer.
Det er imidlertid behov for nye studier av dette, da det er relativt få økonomiske evalueringer som fokuserer spesifikt på depresjon og der iKAT sammenlignes med ordinær KAT (Donker et al., 2015).

\section{Akseptabilitet}

Når en skal evaluere implementeringen av en ny behandlingsform er vurdering av hvorvidt behandlingen er akseptabel for pasientene helt sentralt. Akseptabilitet og hvordan behandlingen virker vil alltid være nært forbundet, men akseptabilitet vil være særlig viktig for den kliniske effektiviteten av en behandlingsform i ordinær praksis sammenlignet med effekten man kan oppnå i kliniske effektstudier (Kaltenthaler et al., 2008). Om pasienten opplever behandlingen som meningsfull, praktisk giennomførbar og relevant vil derfor være en spesielt viktig faktor ved implementering i ordinær praksis.

For brukere av selvhielpsprogrammer kan det knytte seg usikkerhet til om de får like god hjelp som ved ansikt-til-ansikt-behandling (Musiat et al., 2014). Flere studier har imidlertid rapportert positive forventninger og høy brukertilfredshet, og en metaanalyse fra 2018 konkluderer med at iKAT er effektiv, akseptabel og praktisk giennomførbar som depresionsbehandling i primærhelsetienesten (Andrews et al., 2018). Etterlevelsen ble vurdert å være tilfredsstillende selv om den riktignok er lavere i ordinær praksis enn i kliniske studier. For de som fullfører behandlingen er akseptabiliteten lik i kliniske studier og i ordinær praksis. En nylig publisert metaanalyse gir ytterligere støtte for iKAT's effektivitet og akseptabilitet ved behandling av pasienter i ordinær praksis (Etzelmueller et al., 2020).

I deler av verden har store avstander til behandlingstilbud spilt en særlig viktig rolle i utviklingen av telemedisinske og internettbaserte behandlingstilbud. Redusert reisetid til behandling synes å kunne påvirke akseptabilitet for iKAT-programmer positivt og flere studier har vist at programmene har god effekt også for personer som bor i rurale strøk (Vallury et al., 2015). Tilsvarende kan geografiske forhold ha betydning for tilgiengelighet av behandling i deler av Norge med spredt bosetning. I Agder har Felles telemedisinsk losning på Agder (Telma) blitt startet som et prosjekt for å imøtekomme behovet for avstandsoppfølging, i første omgang for personer med kroniske somatiske lidelser. Telma har senere initiert et eget prosjekt for oppfølging av personer med psykiske helseplager, der bl.a. iFightDepression tilbys som et veiledet selvhielpsverktøy mot depresjon (Telma, 2018).

Videre er det aktuelt å drøfte om man kan nå bredere ut med behandling ved at iKAT senker tersklene for hjelpsøking for spesifikke grupper som i mindre grad enn den øvrige befolkningen oppsøker eller mottar hjelp. Det er godt dokumentert at menn søker hielp for psykiske plager i mindre grad enn kvinner (Reneflot et al., 2018). Likeens, og til tross for høy grad av rapport- 


\section{Veiledet internettbasert behandling tilbyr en viss grad av anonymitet ved at kontakten med helsepersonell for eksempel kan foregå over telefon. Dette kan styrke akseptabilitet for noen grupper der stigma er en hindring for å oppsøke hielp}

erte psykiske helseplager (Reneflot et al., 2018), viser studier av innvandreres bruk av primær- og spesialisthelsetjenester at innvandrere i mindre grad enn den øvrige befolkningen søker hjelp for psykiske plager (Abebe et al., 2017; Straiton et al., 2014).

Barrierene for hielpsøking vil variere mellom disse gruppene, men en fellesnevner kan være terskler knyttet til stigma ved det å søke hjelp. Veiledet internettbasert behandling tilbyr en viss grad av anonymitet ved at kontakten med helsepersonell for eksempel kan foregå over telefon. Dette kan styrke akseptabilitet for noen grupper der stigma er en hindring for å oppsøke hielp (Mojaverian et al., 2013; Sun et al., 2016).

Eksisterende forskning på akseptabilitet viser tegn på at iKAT kan være et godt alternativ for noen grupper (Jonassaint et al., 2017; Kayrouz et al., 2018), mens det foreløpig ikke er direkte dokumentert at menn favoriserer nettbasert behandling framfor ordinær samtaleterapi (Löbner et al., 2018; Musiat et al., 2014). Det er behov for studier som mer direkte og spesifikt undersøker iKAT vs. KAT, både med tanke på kulturell bakgrunn og kiønn, samt studier som sier noe om hvordan kulturelle tilpasninger av programmene kan styrke akseptabilitet for disse gruppene.

\section{Implementering av iKAT. Erfaringer og utfordringer.}

Implementering kan defineres som et sett av spesifiserte aktiviteter som skal til for å etablere og vedlikeholde en intervension i ordinær praksis (Fixsen et al., 2005). For å oppnå fullgod behandlingseffekt i ordinær praksis er høy implementeringskvalitet en forutsetning (Durlak \& DuPre, 2008). Implementeringskvaliteten avhenger til dels av de praktiske rammene som utgiør konteksten for giennomføringen av intervensjonen: hvorvidt ledelsen støtter den nye praksisen og giør nødvendige ressurser og støttestrukturer tilgiengelige, samt at det gis tilstrekkelig opplæring og veiledning i behandlingsmetoden. Både behandlernes og pasientenes motivasion for giennomføringen av behandlingsintervensjonen står sentralt. Videre avhenger implementeringskvaliteten av hvorvidt behandlingsintervensjonen leveres til målgruppen i samsvar med de retningslinjer som er fulgt i randomiserte kontrollerte studier (Sørlie et al., 2010), riktignok med en viss grad av fleksibilitet slik at intervensjonen kan tilpasses lokale forhold og pasientens behov.
I litteraturen beskrives det en rekke utfordringer ved implementering av iKAT i de ordinære helsetjenestene. Selv om iKAT intensjonelt skal være kostnadseffektivt, tidsbesparende, giøre den kliniske hverdagen enklere og tilgjengeliggiøre depresjonsbehandling (Andersson et al., 2009), innebærer iKAT en helt ny måte for helsepersonell å levere psykologisk behandling på. iKAT er ikke en del av de vanlige rutinene og behandlere er ofte skeptiske til å ta i bruk nye systemer som krever økt kompleksitet, innsats og tid (Mair et al., 2012; Titzler et al., 2018). Helsevesenet har til nå i begrenset grad vært forberedt på å integrere iKAT i eksisterende systemer (Drozd et al., 2016; Titzler et al., 2018). Vanskeligheter med å frigiøre kapasitet til implementeringsarbeidet kan giøre overgangen fra effekt- til effektivitetsstudier i det ordinære helsevesenet utfordrende, og kanskje særlig i primærhelsetienesten (Roy-Byrne et al., 2003).

I primærhelsetjenesten preges den kliniske hverdagen av variert og hektisk arbeid med korte pasientkonsultasjoner og konkurrerende arbeidsoppgaver. I motsetning til spesialiserte iKAT-klinikker hvor iKAT utgiør hovedbehandlingen, vil iKAT i mange tilfeller representere en mindre andel av den totale arbeidsmengden i primærhelsetjenesten. Vi vet at tidsmangel, konkurrerende arbeidsoppgaver og utydelige prioriteringer utgiør en trussel for implementering av nye intervensioner generelt (Sørlie et al., 2010). Dette gielder også for implementering av iKAT med innvirkning på behandlers mulighet og motivasion til å sette seg inn i bruken av iKAT og etterlevelsen av selve behandlingen (Titzler et al., 2018). Med andre ord har dette konsekvenser for hvorvidt behandleren tar i bruk verktøyet og hvorvidt behandlingen giennomføres som tiltenkt.

Vellykket implementering avhenger ikke kun av behandlernes deltakelse og av hvordan systemet legger til rette for denne typen behandling, men også av pasientfaktorer. Noen studier har vist at pasienter kan oppleve iKAT som mindre viktig enn ordinær samtaleterapi og føler seg dermed neglisiert når de tilbys iKAT (Apolinário-Hagen et al., 2018). Manglende oppfølging fra pasientens side grunnet lav motivasjon og forpliktelse kan medføre svak behandlingseffekt (Etzelmueller et al., 2018). Enkelte pasienter opplever å bli overveldet, presset og stresset av egenarbeidet (Etzelmueller et al., 2018), mens andre opplever at arbeidet er for fleksibelt og dermed lett å utsette (Littlewood et al., 2015). Faktorer ved sykdomsforløpet som alvorlighetsgrad, kronisitet, suicidalitet og komorbide vansker kan vanskeliggiøre behandlingen (Titzler et al., 2018).

Denne og den neste delen er skrevet med utgangspunkt i litteraturgjennomgangen gjort i Gjernes \& Wernø Nilsson (2019). 


\section{Tiltak for å styrke implementering av iKAT.}

Med utgangspunkt i de erfaringene som er giort med implementering av iKAT synes det særlig aktuelt å sette inn tiltak på to områder; 1) opplæring og oppfølging av behandlerne etter at de har tatt verktøyet i bruk (Drozd et al., 2016; Wilhelmsen et al., 2014) og 2) tiltak som øker brukervennlighet og pasientens motivasjon og forpliktelse (Etzemueller et al., 2018; Titzler et al., 2018).

Opplæring og videre oppfølging av veilederne bør gi en grundig oversikt over verktøyet og den praktisk/ tekniske bruken. Helt sentralt i opplæringen er at veilederne får kunnskap om teori- og evidensgrunnlaget for iKAT (Wilhelmsen et al., 2014), og at man har et særlig fokus på veilederens rolle når det gielder innhold og omfang i veiledningen. Mye tyder på at oppfølging av veilederne er like viktig som selve grunnopplæringen (Gjernes \& Wernø Nilsson, 2019). Eksempelvis er grunnopplæringen for veiledere av iFightDepression relativt kort (beregnet til ca. 2 timer, se https://ifightdepression. com/no/helsepersonell/online-opplaering-i-ifightdepression). Videre oppfølging av veilederne kan være i form av nyhetsbrev, tilgiengelig veiledermanual, veiledersamlinger og direkte kontakt. Studier av implementering anbefaler også at man rekrutterer noen utvalgte nøkkelveiledere (Gjernes \& Wernø Nilsson, 2019). Dette kan være veiledere som har vist særlig interesse for å implementere intervensionen i sin egen praksis og som har skaffet seg en del erfaring og trygghet med praktisk bruk av verktøyet. Disse nøkkelveilederne vil etter hvert kunne bidra i oppfølgingen av andre veiledere, for eksempel overfor kollegaer i psykiske helse- og rustjenesten i en kommune.

Verktøyet må være enkelt å bruke og finne fram i for pasientene. Siden målgruppen er personer med depresjon, med utfordringer knyttet til konsentrasjon og energiløshet, bør formidlingen være effektiv og direkte ved å veksle mellom tekst, grafikk og lyd-/videofiler. Dersom brukeren opplever tekniske problemer, f.eks. ved innlogging eller utfylling/lagring av arbeidsark, må veien til IT-støtte være kort (Titzler et al., 2018). Veilederen bør ha fokus på motivasjon hos pasienten, blant annet bør verktøyet ha funksionalitet som viser brukerens progresion (Etzelmueller et al., 2018).

\section{Overordnete prioriteringer og systematisk implementering}

I tillegg til bottom-up tiltakene som er foreslått rettet mot veiledere/helsepersonell og pasientene vil implementering avhenge av overordnede prioriteringer i helsevesenet. Et eksempel på dette er Rask psykisk helsehjelp som tilbys av flere norske kommuner og som innebærer korttidsbehandling basert på veiledet selvhielp og kognitiv atferdsterapi.

Veiledete selvhjelpsprogrammer har i lengre tid vært satt på agendaen som et mulig tiltak for å nå ut til flere med behandling for personer med milde til moderate psykiske lidelser, deriblant depresion (Helse- direktoratet, 2009). Helsedirektoratet fikk i 2015 i oppdrag å bidra til at det etableres slik behandling og initierte sammen med Direktoratet for e-helse et prosjekt som skal legge til rette for bruk av digitale verktøy innen psykisk helse i primærhelsetjenesten (Regieringen, 2017). De tekniske og organisatoriske løsningene skal være slik at verktøyene blir lett tilgiengelige for behandlere og brukere, og slik at behandlere kan ta dem i bruk innenfor en faglig forsvarlig ramme (Regjeringen, 2017).

På Helsenorge.no er det nå utviklet en egen verktøykatalog. Her finnes det allerede en rekke åpne selvhjelpsverktøy, dvs. at de er tilgiengelige for alle uten noen form for innlogging eller involvering av en helsearbeider. iFightDepression-verktøyet, som eksempel på et veiledet selvhjelpsverktøy, er også tilgiengelig fra denne katalogen. Veilederen kan sende iFightDepression til brukeren giennom den såkalte Verktøyformidleren, som er en egen applikasion for helsepersonell på Helsenorge.no.

Utviklingen av denne type tienester må sees i sammenheng med den generelle satsningen på e-helse i Norge der digitale plattformer for spredning og innovasjon av velferdsteknologi er ett av tiltaksområdene (Direktoratet for e-helse, 2017). Ved å giøre veiledet selvhielpsprogrammer tilgiengelig og kjent fra Helsenorge.no, som er en portal for samlet informasion om helsetienester på nett, kan vi forvente at denne type tjenester når ut vesentlig bredere enn til nå, både til brukerne selv og til behandlere i primærhelsetjenesten som skal veilede i bruken. Et annet viktig aspekt ved å samle verktøy på en felles plattform er at dette vil gi muligheter for å sette standarder for kvalitet, med hensyn til brukervennlighet, datasikkerhet/personvern og faglig forsvarlighet og innhold.

Til tross for omfattende litteratur om implementeringskvalitet, er det behov for et okt fokus på hvordan endring implementeres i helsevesenet (Lau et al., 2016). For å forstå hvordan intervensjoner forårsaker endring, er det behov for et teoretisk rammeverk (Craig et al., 2008). Uten en teoretisk forankring begrenses mulighetene for å identifisere faktorer som predikerer sannsynligheten for vellykket implementering og utvikling av gode implementeringsstrategier (Nilsen, 2015). Normalization process theory (NPT) er et eksempel på en teori som er utviklet for å systematisk kunne studere implementering av ny helseteknologi (Finch et al., 2013). NPT identifiserer sentrale faktorer som fremmer og hindrer normaliseringen av komplekse intervensjoner i klinisk praksis. Normalisering er prosessen hvor ny praksis integreres i eksisterende praksis og omgiøres til innlærte rutiner (May \& Finch, 20o9). NPT vektlegger viktigheten av at behandlerne opplever intervensjonen som meningsfull, engasjerende, praktisk giennomførbar og at implementeringen monitoreres kontinuerlig og gir mulighet for tilpasninger. Gjernes og Wernø Nilsson (2019) fant i en studie basert på NPT at engasjement, gode praktiske rammebetingelser, samt monitorering 
og mulighet for tilpasning signifikant predikerte behandlernes bruk av iKAT. Dette tyder på at en systematisk implementeringsstrategi som vektlegger disse elementene vil kunne bedre implementeringen av iKAT.

\section{Konklusjoner}

Oppsummert har forskningen vist at veiledet selvhielp for mild til moderat depresjon er like effektiv som ved ordinær kognitiv atferdsterapi. Behandlingen er akseptabel for pasienten, men det er behov for mer kunnskap om hva innholdet i og omfanget av veiledningen bør være for å redusere drop-out og styrke etterlevelse. Det vil fortsatt være interesse for studier av effektiviteten av enkeltverktøy sammenlignet med annen aktiv behandling, men særlig nyttig vil det være å undersøke pasientenes og veiledernes tilfredshet (Justicia et al., 2017; Oehler et al., 2019) for å kunne giøre verktøyene mer brukervennlige og veiledningen mer effektiv.

Nasjonale planer for e-helse vil giøre verktøyene mer tilgiengelige og forhåpentligvis påvirke beslutningstagere i helsevesenet til å giøre nødvendige prioriteringer slik at slike verktøy blir mer normale å bruke. Vi tror imidlertid ikke at dette alene er nok. Fraværet av kunnskap om implementering av iKAT kan innebære en hindring for vellykket spredning i stor skala (Hadjistavropoulos, et al., 2017). Dersom det kommunale helse- og omsorgstilbudet skal utvides og styrkes ved å ta i bruk iKAT som behandling for depresion, bør en ha fokus på implementeringsprosessen, fordi man uten et slikt fokus i denne konteksten vil ha mindre kontroll over hvordan metoden praktiseres. Det vil være behov for prosjekter som jobber mer systematisk med og evaluerer implementeringstiltak, slik at man på sikt kan utarbeide en tydelig implementeringsstrategi.

\section{REFERANSER}

Abebe, D. S., Lien, L., \& Elstad, I. I. (2017). Immigrants' utilization of specialist mental healthcare according to age, country of origin, and migration history: a nation-wide register study in Norway. Soc Psychiatry Psychiatr Epidemiol, 52(6), 679-687. doi: 10.1007/s00127-017-1381-1.

Andersson, G., Carlbring, P., Berger, T., Almlöv, I., \& Cuijpers, P. (2009). What Makes Internet Therapy Work? Cognitive Behaviour Therapy, 38(sup1), 55-6o. doi: 10.1080/16506070902916400

Andersson, G., Cuijpers, P., Carlbring, P., Riper, H., \& Hedman, E. (2014). Guided Internet-based vs. face-to-face cognitive behavior therapy for psychiatric and somatic disorders: a systematic review and meta-analysis. World Psychiatry, 13(3), 288-295. doi: 10.1002/wps.20151.

Andrews, G., Basu, A., Cuijpers, P., Craske, M. G., McEvoy, P., English, C. L., \& Newby, I. M. (2018). Computer therapy for the anxiety and depression disorders is effective, acceptable and practical health care: An updated meta-analysis. Journal of Anxiety Disorders, 55, 70-78. doi: https://doi. org/10.1016/i.janxdis.2018.01.001

Apolinário-Hagen, I., Fritsche, L., Bierhals, C., \& Salewski, C. (2018). Improving attitudes toward e-mental health services in the general population via psychoeducational information material: A randomized controlled trial. Internet Interventions, 12. doi: 10.1016/j.invent.2017.12.002

Craig, P., Dieppe, P., Macintyre, S., Michie, S., Nazareth, I., \& Petticrew, M. (2008). Developing and evaluating complex interventions: the new Medical Research Council guidance. BMI, 337, a1655. doi: 10.1136/bmi.a1655
Cuijpers, P., Donker, T., van Straten, A., Li, I., \& Andersson, G. (2010). Is guided self-help as effective as face-to-face psychotherapy for depression and anxiety disorders? A systematic review and meta-analysis of comparative outcome studies. Psychological Medicine, 40(12), 1943-1957. doi: 10.1017/So033291710000772

Cuijpers, P., van Straten, A., Andersson, G., \& van Oppen, P. (2008). Psychotherapy for depression in adults: A meta-analysis of comparative outcome studies. Journal of Consulting and Clinical Psychology, 76(6), 909-922. doi: 10.1037/a0013075

Direktoratet for e-helse. (2017). Nasional handlingsplan for e-helse 2017-2022 (Vol. IE-1015).

Donker, T., Blankers, M., Hedman, E., Ljótsson, B., Petrie, K., \& Christensen, H. (2015). Economic evaluations of Internet interventions for mental health: a systematic review. Psychological Medicine, 45(16), 3357-3376. doi: 10.1017/ SoO33291715001427

Drozd, F., Vaskinn, L., Bergsund, H. B., Haga, S. M., Slinning, K., \& Bjorkli, C. A. (2016). The Implementation of Internet Interventions for Depression: A Scoping Review. I Med Internet Res, 18(9), e236. doi: 10.2196/imir.5670

Durlak, I. A., \& DuPre, E. P. (2008). Implementation matters: a review of research on the influence of implementation on program outcomes and the factors affecting implementation. Am I Community Psychol, 41(3-4), 327-350. doi: $10.1007 /$ s10464-008-9165-0

Etzelmueller, A., Radkovsky, A., Hannig, W., Berking, M., \& Ebert, D. D. (2018). Patient's experience with blended video- and internet based cognitive behavioural therapy service in routine care. Internet Interventions, 12, 165-175. doi: https://doi.org/10.1016/i.invent.2018.01.003

Etzelmueller A., Vis, C., Karyotaki, E., Baumeister, H., Titov, N., Berking, M., ... Ebert, D. D. (2020). Effects of Internet-Based Cognitive Behavioral Therapy in Routine Care for Adults in Treatment for Depression and Anxiety: Systematic Review and Meta-Analysis. I Med Internet Res. 2020;22(8):e18100. doi:10.2196/18100.

Finch, T. L., Rapley, T., Girling, M., Mair, F. S., Murray, E., Treweek, S., . . . May, C. R. (2013). Improving the normalization of complex interventions: measure development based on normalization process theory (NoMAD): study protocol. Implementation Science, 8(1), 43. doi: 10.1186/1748-5908-8-43

Fixsen, D. L., Naoom, S. F., Blasé, K. A., Friedman, R. M., \& Wallace, F. (2005). Implementation research: A synthesis of the literature. Tampa, FL: University of South Florida.

Giernes, S. A., \& Wernø Nilsson, H. S. (2019). Veiledet internettbasert selv hielp i primærhelsetienesten. (Hovedoppgave), Universitetet i Oslo, Oslo.

Hadjistavropoulos, H. D., Nugent, M. M., Dirkse, D., \& Pugh, N. (2017). Implementation of internet-delivered cognitive behavior therapy within community mental health clinics: a process evaluation using the consolidated framework for implementation research. BMC Psychiatry, 17(1), 331. doi: 10.1186/s12888-017-1496-7

Helsedirektoratet. (2009). Nasjonale retningslinjer for diagnostisering og behandling av voksne med depresjon i primær-og spesialisthelsetienesten Nasjonale retningslinier (Vol. IS-1561): Helsedirektoratet.

Iohansson, R., \& Andersson, G. (2012). Internet-based psychological treatments for depression. Expert Review of Neurotherapeutics, 12(7), 861-870. doi: 10.1586/ern.12.63

Ionassaint, C. R., Gibbs, P., Belnap, B. H., Karp, J. F., Abebe, K. K., \& Rollman B. L. (2017). Engagement and outcomes for a computerised cognitive-behavioural therapy intervention for anxiety and depression in African Americans. BJPsych Open, 3(1), 1-5. doi: 10.1192/bipo.bp.116.003657

Iusticia, A., Elices, M., Cebria, A. I., Palao, D. I., Gorosabel, J., Puigdemont, D.,

. Pérez, V. (2017). Rationale and methods of the iFightDepression study: A double-blind, randomized controlled trial evaluating the efficacy of an internet-based self-management tool for moderate to mild depression. BMC Psychiatry, 17(1), 143. doi: 10.1186/s12888-017-1306-2

Kaltenthaler, E., Sutcliffe, P., Parry, G., Beverley, C., Rees, A., \& Ferriter, M. (2008). The acceptability to patients of computerized cognitive behaviour therapy for depression: a systematic review. Psychological Medicine, 38(11), 1521-1530. doi: 10.1017/So033291707002607 
Kayrouz, R., Dear, B. F., Karin, E., Fogliati, V. J., Gandy, M., Keyrouz, L., . . . Titov, N. (2018). Acceptability of Mental Health Services for Anxiety and Depression in an Arab Sample. Community Mental Health Journal, 54(6), 875-883. doi: 10.1007/s10597-018-0235-y

Kessler, R. C., Merikangas, K. R., \& Wang, P. S. (2007). Prevalence, Comorbidity, and Service Utilization for Mood Disorders in the United States at the Beginning of the Twenty-first Century. Annual Review of Clinical Psychology, 3(1), 137-158. doi: 10.1146/annurev.clinpsy.3.022806.og1444

Lau, R., Stevenson, F., Ong, B. N., Dziedzic, K., Treweek, S., Eldridge, S., .. Murray, E. (2016). Achieving change in primary care-causes of the evidence to practice gap: systematic reviews of reviews. Implementation Science, 11(1), 40. doi: 10.1186/s13012-016-0396-4

Littlewood, E., Duarte, A., Hewitt, C., Knowles, S., Palmer, S., Walker, S., ... Gilbody, S. (2015). A randomised controlled trial of computerised cognitive behaviour therapy for the treatment of depression in primary care: the Randomised Evaluation of the Effectiveness and Acceptability of Computerised Therapy (REEACT) trial. Health Technol Assess, 19(101). doi: 10.3310/hta191010

Löbner, M., Pabst, A., Stein, I., Dorow, M., Matschinger, H., Luppa, M., . . . Riedel-Heller, S. G. (2018). Computerized cognitive behavior therapy for patients with mild to moderately severe depression in primary care: A pragmatic cluster randomized controlled trial (@ktiv). Journal of Affective Disorders, 238, 317-326. doi: https://doi.org/10.1016/j.jad.2018.06.008

Mair, F. S., May, C., O'Donnell, C., Finch, T., Sullivan, F., \& Murray, E. (2012). Factors that promote or inhibit the implementation of e-health systems: an explanatory systematic review. Bulletin of the World Health Organization, 9o(5), 357-364. doi: 10.2471/BLT.11.099424

May, C., \& Finch, T. (2009). Implementing, Embedding, and Integrating Practices: An Outline of Normalization Process Theory. Sociology-the Journal of The British Sociological Association - SOCIOLOGY, 43, 535-554. doi: $10.1177 / 0038038509103208$

Mojaverian, T., Hashimoto, T., \& Kim, H. (2013). Cultural Differences in Professional Help Seeking: A Comparison of Japan and the U.S. Frontiers in Psychology, 3(615). doi: 10.3389/fpsyg.2012.00615

Musiat, P., Goldstone, P., \& Tarrier, N. (2014). Understanding the acceptability of e-mental health--attitudes and expectations towards computerised self-help treatments for mental health problems. BMC Psychiatry, 14, 109. doi: 10.1186/1471-244X-14-109

Nilsen, P. (2015). Making sense of implementation theories, models and frameworks. Implementation Science, 10(1), 53. doi: 10.1186/s13012-015-0242-0

Oehler, C., Görges, F., Böttger, D., Hug, I., Koburger, N., Kohls, E., \& RummelKluge, C. (2019). Efficacy of an internet-based self-management intervention for depression or dysthymia - a study protocol of an RCT using an active control condition. BMC Psychiatry, 19(1), 9o. doi: 10.1186/s12888-019-2063-1

Regieringen. (2017). Mestre hele livet. Regjeringens strategi for god psykisk helse (2017-2022).

Regieringen. (2020). Handlingsplan for forebygging av selvmord 20202025. Reneflot, A., Aaro, L. E., Aase, H., Reichborn-Kiennerud, T., Tambs, K., \& Overland, S. (2018). Psykisk helse i Norge: Folkehelseinsituttet.

Roy-Byrne, P. P., Sherbourne, C. D., Craske, M. G., Stein, M. B., Katon, W., Sullivan, G., .. Bystritsky, A. (2003). Moving Treatment Research From Clinical Trials to the Real World. Psychiatric Services, 54(3), 327-332. doi: 10.1176/appi.ps.54.3.327

Straiton, M., Reneflot, A., \& Diaz, E. (2014). Immigrants' use of primary health care services for mental health problems. BMC Health Services Research, 14(1), 341. doi: 10.1186/1472--14-341

Sun, S., Hoyt, W. T., Brockberg, D., Lam, I., \& Tiwari, D. (2016). Acculturation and enculturation as predictors of psychological help-seeking attitudes (HSAs) among racial and ethnic minorities: A meta-analytic investigation. Journal of Counseling Psychology, 63(6), 617-632. doi: 10.1037/couoooo172

Sørlie, M. A., Ogden, T., Solholm, R., \& Røyrhus, A. O. (2010).

Implementeringskvalitet - om å få tiltak til å virke: En oversikt. Tidsskrift for

Norsk Psykologforening(47), 315-321.
Telma. (2018). Felles telemedisinsk løsning på Agder. Informasion for helsepersonell. 2020

Titzler, I., Saruhanjan, K., Berking, M., Riper, H., \& Ebert, D. D. (2018). Barriers and facilitators for the implementation of blended psychotherapy for depression: A qualitative pilot study of therapists' perspective. Internet Interv, 12, 150-164. doi: 10.1016/i.invent.2018.01.002

Vallury, K. D., Jones, M., \& Oosterbroek, C. (2015). Computerized Cognitive Behavior Therapy for Anxiety and Depression in Rural Areas: A Systematic Review. I Med Internet Res, 17(6), e139. doi: 10.2196/imir.4145

Varga, A., Toth, M., Czegledi, E., Erdelyi, K., Szeifert, N., Gyomber, S., \& Purebl, G. (2020). Adherence to the iFightDepression Online Selfhelp Tool for Mild and Moderate Depression. Submitted PloS One.

Wilhelmsen, M., Høifodt, R. S., Kolstrup, N., Waterloo, K., Eisemann, M., Chenhall, R., \& Risør, M. B. (2014). Norwegian general practitioners' perspectives on implementation of a guided web-based cognitive behavioral therapy for depression: a qualitative study. Journal of medical Internet research, 16(9), e2o8-e2o8. doi: 10.2196/imir.3556

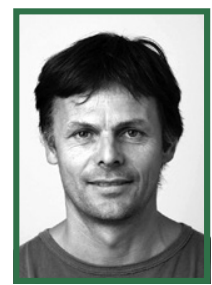

EGIL HAGA jobber som seniorrådgiver ved Nasjonalt senter for selvmordsforskning og -forebygging

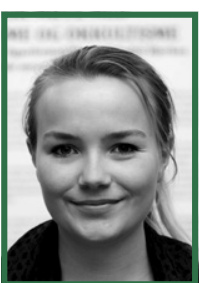

HANNE SOFIE WERN $\varnothing$ NILSSON er psykolog ved Vinderen DPS og vitenskapelig assistent ved Nasjonalt senter for selvmordsforskning og -forebygging

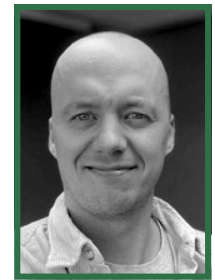

SIMEN AURSTAD GJERNES er psykolog på A-senterets poliklinikk i Oslo, med ansvar for utredning og behandling av pasienter med rusproblematikk og psykiske lidelser.

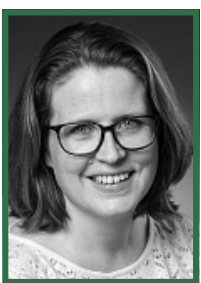

INGUNN LEGARD er prosjektkoordinator ved Nasjonalt senter for selvmordsforskning og -forebygging, Institutt for klinisk medisin, Universitetet i Oslo. 